www.jmscr.igmpublication.org Impact Factor 5.84 Index Copernicus Value: 71.58 ISSN (e)-2347-176x ISSN (p) 2455-0450 crossref DOI:

\title{
The Knowledge and Preference of Postendodontic Restorations: A Survey study among General Practitioners in Governmental Universities
}

\author{
Authors \\ Sultanah Al Mobarak ${ }^{1}$, Alhanouf Alshamsan², Lama Alghufaily ${ }^{2}$, Nouf Alsalem², \\ Nourah Alfuraih ${ }^{2}$, Sarah Albluwi ${ }^{2}$, Shahad Aladhyani ${ }^{2}$, Amal Sakr ${ }^{3}$, \\ Neamat Abu-bakr ${ }^{4}$ \\ ${ }^{1}$ General Dentist, Department of Clinical Dental Science, College of Dentistry, PNU \\ ${ }^{2} 4^{\text {th }}$ year Dental Student, College of Dentistry, PNU \\ ${ }^{3}$ Assistant Professor, Department of Clinical Dental Science, College of Dentistry, PNU \\ ${ }^{4}$ Professor, Department of Clinical Dental Science, College of Dentistry, PNU
}

\section{Introduction}

Endodontic therapy is the removal of irreversibly inflamed or necrotic pulp tissue from the root canals. Future contamination of the endodotically treated teeth is a major and primary concern because of the high chance of oral cavity contamination to invade the tooth after Endodontic treatment which can be prevented by restoring the tooth immediately with no delays. The placement of this restoration returns the tooth to normal function and esthetic and maintain it against any further destruction as it becomes weaker after the pulp removal. Due to structural and morphological differences between vital and non-vital root-filled teeth, restoration of these endodontically treated teeth can be challenging. ${ }^{(2)}$ consequently, the quality of both endodontic treatment and tooth restoration have a heavy influence on the treatment outcome and prognosis. Recently coronal restorations of the teeth are rapidly growing and increasing in number, making the decision of choice more difficult to the dentist to obtain a restoration with a good quality to reach the maximum effectiveness. The choice of restoration depends on several situations and factors including mainly the amount of remaining tooth and the type of tooth and this requires special considerations ${ }^{(6)}$ emphasizing that the prognosis of endodontically treated teeth is largely influenced by the postendodontic restoration and not only the endodontic procedure its self ${ }^{(7-9)}$.

\section{Objective}

The aim of this questionnaire-based study is to evaluate the knowledge, preferences and current strategies used in terms of restoring endodontically treated teeth (ETT) among general practitioners in governmental universities in Riyadh.

\section{Materials \& Methods}

To collect data, a standard questionnaire basedsurvey containing 7 questions "5-point scale and multiple choice questions" was distributed to evaluate the knowledge and preference in terms of restoring endodontically treated teeth (ETT). 
The questionnaire was rephrased from several previous study, modifications were made to suit the current requirements of the present study ${ }^{(6,10)}$. The results were analyzed by IBM SPSS version.

\section{Result}

Seventy three (73) questionnaires were distributed by hand out of which fifty four (54) were received among the participants, giving a response rate of $(74 \%)$.

\section{Discussion}

The present survey was conducted to evaluate the current knowledge and preference of general practitioners of governmental universities in Riyadh concerning the restoration of endodontically treated teeth. According to the questionnaire, it is shown that the decision to place an endodontic post is hugely affected by the existing substance defect, tooth type and restorative material.

As mentioned previously, 54 questionnaires were evaluated in this study, which is a relatively small sample size in comparison to the studies we reviewed that were of the same interest. In this study, the response rate was $74 \%$ which is less than the response rate of the reviewed studies $(100 \%)$ due to the difficulties faced while approaching the target group.

When asked about the frequency of post used, (35.2\%) chose to place it in molars. In contrast to the reviewed studies most of the participants chose Abutment in FDP (independent of tooth type). In terms of substance defect, most of the participants prefer post when only one coronal wall remains in anterior teeth. In contrast to the reviewed studies $(46.3 \%)$ prefer it when only one coronal wall remains in premolar. This emphasize the recommendations in the current literature, in which endodontic posts are less frequently placed as anchorage for a supraconstruction in endodontically treated molars than in anterior teeth and premolars. The reason for this is a larger retentive surface, resulting from a relatively large pulp cavity, as well as the fact that vertical forces dominate in the posterior dentition, while shear forces occur hardly at all ${ }^{(11)}$.

Also, $(46.3 \%)$ of the participants would very often restore an endodontically treated teeth with a crown on molars. The reviewed studies from Switzerland shared the same opinion as most of them prefer to restore a molar teeth with a crown. On the basis of the restorative materials used for endodontically treated posterior teeth the most common was prefabricated post and tooth colored crown. According to the recommendations of the literature on this topic, one retrospective clinical study showed that endodontically treated teeth without crown restorations had a 6-times higher failure rate after ten years ${ }^{(12)}$. Similarly, Nagasiri \& Chitmongkolsuk (2005) also found that crowned, non-vital molars had a higher survival probability than directly restored molars ${ }^{(13)}$.

Zinc phosphate cement was the most preferable luting material that is used for intracanal metal post, in contrast the reviewed studies chose glassionomer cement $(37.9 \%)$ over the rest of the choices. On the other hand when it comes to luting fiber post it was a point of agreement where composite based cement was their preferable choice $(66.3 \%)$.

A clinical case was presented in the survey provided with pictures regarding the choice of restoration for a large MOD cavity in a premolar and molar tooth. Most participants would place a post and core buildup and crown as a definitive restoration. In contrast to the reviewed studies, they preferred Post-and-core build-up and crown for premolar and composite build-up for molar as a definitive restoration. These results are supported by the literature stating that despite the greater technical efforts and the limited esthetic outcomes, cast post-and-core build-ups can still be recommended as an alternative in postendodontic restoration, as they have a survival rate of over $90 \%$ after eight years ${ }^{(14)}$.

Regardless of all these differences and various options, because of the nature of daily dental 
practice, patient's wishes and financial situation can have a huge influence on the decision making.

\section{Conclusion}

The study was conducted to evaluate the current knowledge and preference regarding the restoration of endodontically treated teeth. Until an ETT is restored to full function, treatment is incomplete. The unrestored ETT is susceptible to fracture, which could lead to loss of tooth. Maximum preservation of healthy tooth structure and use of restorative materials with mechanical properties similar to the dental structure favor greater longevity of tooth restoration complex ${ }^{(15)}$. Therefore, Within the limitations of the present study, it was concluded that most of the participants agreed to place on intracanal post based on the remaining tooth the substances and the tooth type.

In addition, most of the participants would prefer to restore endodontically treated molar teeth with a crown.

In terms of restorative material used to restore endodontically treated posterior teeth, prefabricated post and tooth colored crown was predominantly used.

Regardless of post type, composite based cements were the most commonly used luting cement.

Most of the participants thought that endodontic failure is the most common cause for failure of restored endodontically treated teeth.

Further studies on a larger sample size and more clinical longitudinal trials are required to decide the best method for restoration of endodontically treated teeth.

\section{References}

1. Spielman, H., Schaffer, S., Cohen, M., Wu, H., Vena, D., Collie, D., Curro, F., Thompson, V. and Craig, R. (2012). Restorative outcomes for endodontically treated teeth in the Practitioners Engaged in Applied Research and Learning Network. The Journal of the American Dental Association, 143(7), pp.746-755.
2. Sequeira-Byron, P., Fedorowicz, Z., Alrowaili, E., Nasser, M. and Carter, B. (2015). Single crowns versus conventional fillings for the restoration of root-filled teeth. Cochrane Database Syst Rev., 25(9).

3. Chadwick J, Gonzales A, McLean C, Naghavi A, Rosati S, Yau S. Restoration of endodontically treated teeth: An evidence based literature review. University of Toronto, Faculty of DentistryCommunity, Dentistry 2008;1-21.

4. Heydecke G, Butz F, Hussein A, Strub JR. Fracture strength after dynamic loading of endodontically treated teeth restored with different post-and-core systems. J Prosthet Dent 2002 Apr;87(4): 438-45.

5. Fedorowicz Z, Carter B, de Souza RF, Chaves CA, Nasser M, Sequeira-Byron P. Single crowns versus conventional fillings for the restoration of root filled teeth. Cochrane Database Syst Rev 2012 May;16(5):CD009109

6. kon, M., zitzmann, N., weiger, R. and krastl, G. (2013). Postendodontic restoration: a survey among dentists in Switzerland. Schweiz Monatsschr Zahnmed, 123(12), pp.1076-88.

7. Ray H A, Trope M. Periapical Status of Endodonti- cally Treated Teeth in Relation to the Techni- cal Quality of the Root Filling and the Coro- nal Restoration. Int Endod J 28: 12-18 (1995)

8. Lynch C D, Burke F M, Ni R R, Hannigan A.The In- fluence of Coronal Restoration Type on the Survival of Endodontically Treated Teeth. Eur J Prosthodont Restor Dent 12: 171-176 (2004)

9. Tronstad L, Asbjornsen K, Doving L, Pedersen I, Eriksen H M. Influence of Coronal Restorations on the Periapical Health of Endodontically Treated Teeth. Endod Dent Traumatol 16: 218-221 (2000)

10. Akbar I. Knowledge, Attitudes and Practice of Restoring Endodontically 
Treated Teeth by Dentists in North of Saudi Arabia. International Journal of Health Sciences. 2015;9(1):41-49.

11. Naumann, M., Blankenstein, F., Kießling, S. and Dietrich, T. (2005). Risk factors for failure of glass fiber-reinforced composite post restorations: a prospective observational clinical study. European Journal of Oral Sciences, 113(6), pp.519-524.

12. Aquilino, S. and Caplan, D. (2002). Relationship between crown placement and the survival of endodontically treated teeth. The Journal of Prosthetic Dentistry, 87(3), pp.256-263.

13. Nagasiri R, Chitmongkolsuk S. (2005). Long-Term Survival of Endodontically Treated Molars without Crown Coverage: A Retrospective Cohort Study. Journal of Prosthetic Dentistry93( 2 ), pp. 164-170 .

14. Jung R E, Kalkstein O, Sailer I, Roos M, Hämmerle C H. (2007).A Comparison of Composite Post Buildups and Cast Gold Post-and-Core Buildups for the Restoration of Nonvital Teeth after 5 to 10 Years. The International Journal of Prosthodontics.20 (1), pp: 63-69.

15. VẢrlan C, Dimitriu B, VẢrlan V, Bodnar D, Suciu I. Current opinions concerning the restoration of endodontically treated teeth: basic principles. Journal of Medicine and Life. 2009;2(2):165-172. 